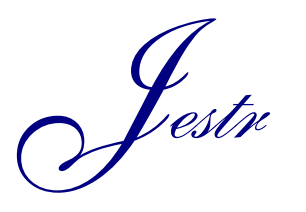

\title{
Preparation and Characterization of Hydrophilic Composite Nanofiltration Membrane by Interfacial Polymerization
}

\author{
Li Xindong ${ }^{1,2}$, Wang Lei ${ }^{1^{*}}$, Huang Wanfu ${ }^{2,3}$, Liang Juan ${ }^{2}$ and Wang Xiaofeng ${ }^{2}$ \\ ${ }^{I}$ School of Environmental \& Municipal Engineering, Xi'an University of Architecture and Technology, Xi'an, 710001, China \\ ${ }^{2}$ School of Architectural and Surveying \& Mapping Engineering, Jiangxi University of Science and Technology, Gan zhou, 341000, China \\ ${ }^{3}$ Department of Chemical Engineering, Faculty of Science and Engineering, Curtin University, Perth, 6102, Australia
}

Received 13 March 2016; Accepted 30 April 2016

\begin{abstract}
Hydrophilic nanofiltration membranes have drawn increasing attention owing to their high flux and anti-fouling characteristics. To improve the hydrophilicity of a polysulfone nanofiltration membrane, inorganic salt sodium phosphate in aqueous phase is added during interfacial polymerization (IP). In this study, hydrophilic composite nanofiltration membranes were prepared through IP and were then characterized in terms of their morphology and performance using scanning electron microscope (SEM), atomic force microscope (AFM), water contact angle, determination of pure water flux, and magnesium ion removal. The improved performance of the membranes was verified in terms of pure water permeability and rejection of inorganic salts. Results showed that the optimal monomer concentrations for different monomers are $1.5 \%$ of sodium phosphate, $1.0 \%$ of PIP, and $0.25 \%$ of $1,3,5$-benzenetricarbonyl trichloride. The optimum reaction time of the aqueous and organic phases can be controlled for $1 \mathrm{~min}$, and the optimum thermal treatment is $70{ }^{\circ} \mathrm{C}$ for $12 \mathrm{~min}$. The SEM, AFM, and hydrophilic testing results indicated that the ultrafiltration substrate membrane surface has a compact and ultrathin functional layer, and the addition of sodium phosphate can improve the hydrophilicity of the resultant membrane. Therefore, inorganic salts, such as sodium phosphate, may be considered a potential additive for enhancing the performance of composite nanofiltration membranes.
\end{abstract}

Keywords: Interfacial polymerization, Nanofiltration membrane, Hydrophilicity

\section{Introduction}

Nanofiltration is a new, functional, semipermeable membrane with properties between ultrafiltration and reverse osmosis membranes, including low operating pressure, high retention characteristics for small organic molecules, and outstanding selectivity of inorganic salt ions of different valences [1]. At present, a series of commercial nanofiltration membranes, such as NTR, UTC, ATF, and MPT, are prepared through interfacial polymerization (IP) in foreign companies [2]. This process is characterized by two highly reactive monomers reacting at the interface of two immiscible polymerizations, forming a thin film on a porous support layer [3]. The performance of the nanofiltration membranes is affected by various factors during preparation, such as the type and microstructure (i.e., pore size, hydrophilicity, and surface morphology) of the base film as well as the type, concentration, solubility, diffusion, or partition coefficients of the monomers, solvent, additives [4,5], and IP conditions [6]. Hydrophilicity is a particularly important characteristic of nanofiltration membranes. The membranes with good hydrophilic properties have excellent

*E-mail address: w10178@126.com ISSN: 1791-2377 @ 2016 Eastern Macedonia and Thrace Institute of Technology. All rights reserved. flux and separation performance, and their membrane fouling can be reduced.

\section{State of the Art}

Polysulfone (PSf) is widely used as a material for ultrafiltration and nanofiltration membranes because of its excellent balance between chemical and mechanical properties [7]. However, the hydrophobic properties of PSf membranes result in low water flux and serious membrane fouling. Over the years, much work has been done to improve membrane separation performance by changing the membrane surface chemistry and morphology to obtain hydrophilic PSf membranes, such as blending with hydrophilic polymers [8] and grafting with hydrophilic groups, including sulfonic acid [9], carboxylic acid [10], and amine group [11]. Previous research used inorganic nanoparticles with good wettability to modify membranes $[12,13]$, but due to aggregation, the nanoparticles in the film were unevenly distributed and even plugged pores, thereby failing to achieve the desired effect. Additives in the aqueous phase can change monomer dissolution and diffusion rates and even take part in cross-linking reactions, thereby playing an important role in determining the performance of nanofiltration membranes.

In this study, composite nanofiltration membranes were prepared through IP with aqueous monomer anhydrous piperazine (PIP) and organic monomer 1,3,5benzenetricarbonyl trichloride (TMC). The inorganic salt of sodium phosphate dissolved in aqueous phase was introduced during IP. The effects of the monomer 
concentration in the two phases, the polymerization reaction time, the thermal treatment time, and temperature on the resultant nanofiltration membrane were investigated to determine the optimum preparation conditions.

\section{Methodology}

\subsection{Materials}

PSf ultrafiltration membrane (Homemade), hexane (Tianjin Zhiyuan Chemical Reagent Co., Ltd., AR), trimesoyl chloride (Qingdao Sanli Beno Chemical Industry Co., Ltd., AR), anhydrous PIP (Shanghai Exhibition Cloud Chemical Co., Ltd., AR), sodium phosphate dodecahydrate (Guangdong Guanghua Science and Technology Co., Ltd., AR), and crystalline magnesium (Da Mao Chemical Reagent Factory in Tianjin, AR) were used as received without further purification.

\subsection{Preparation of nanofiltration membranes}

A certain amount of anhydrous PIP and TMC dissolved in deionized water and hexane, respectively, were selected to prepare a solution of the aqueous and organic phases with the required concentrations. An ultrafiltration membrane was immersed in aqueous solution for a prescribed time and was extracted to remove surface moisture. The membrane was subsequently immersed in a solution of organic phase and was then dried at controlled temperature for a certain time. Finally, when the monomer and solvent on the membrane surface were removed with deionized water, the membrane sample was preserved in deionized water for subsequent characterization.

\subsection{Pure water flux and rejection measurement}

The pure water flux $(J)$ of the hydrophilic composite nanofiltration membrane was determined with the membrane performance evaluation cell. The test pressure was adjusted to $0.6 \mathrm{Mpa}$, and $\mathrm{J}$ was calculated with the following equation:

$J=\frac{V}{A t}$

where $\mathrm{V}$ is the permeate volume $(\mathrm{L}), \mathrm{A}$ is the effective membrane area $\left(\mathrm{m}^{2}\right)$, and $\mathrm{t}$ is the experimental time $(\mathrm{h})$.

Under a pressure difference of 0.6 $\mathrm{MPa}$, the membrane rejection was calculated as follows:

$$
R=1-\frac{C_{1}}{C_{0}}
$$

where $\mathrm{C}_{0}$, and $\mathrm{C}_{1}$ are the concentrations of the feed $(1 \mathrm{~g} / \mathrm{L}$ $\mathrm{MgSO}_{4}$ ) and the permeate solution, respectively. The magnesium concentration was calculated with the standard curve of the magnesium concentration calibrated by a conductivity meter (Shanghai Electronics Scientific Instrument Co., DDS-307A). The membrane performance evaluation cell is schematically shown in Figure 1.

\subsection{Characterization of nanofiltration membrane}

The general membrane morphology was observed using a scanning electron microscope (SEM; S4800, Japan) with a Schottky field emission gun and a Robinson backscatter detector. Cross-sectioned samples were prepared by breaking the membranes in liquid nitrogen. Gold coating was applied to all specimens for $1 \mathrm{~min}$ prior to SEM characterization. The surface morphology of the nanofiltration membranes was determined using a Nanoscope III atomic force microscope (ATM; DI 3000, Digital Instruments) in the contact mode. The membrane contact angle was detected using a JYSP-180 contact angle measuring instrument (Beijing Shengxin Detection Instrument Co.)

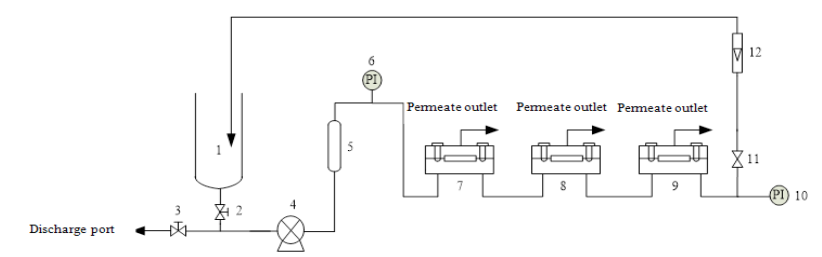

(a) Schematic diagram

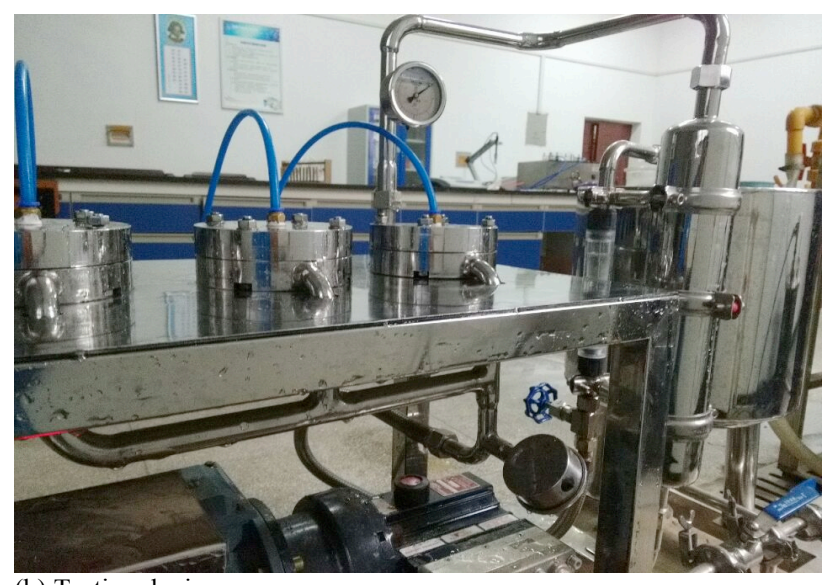

(b) Testing device

Fig. 1 Schematic of the membrane performance evaluation device (Note: 1: Feed liquid tank; 2, 3: Regulating valve; 4: Pressure pump; 5: Buffer; 6, 10: Pressure gauge; 7, 8, 9: Membrane cisterna; 11: Needle valve; 12: Circulating liquid flow meter)

\section{Result Analysis and Discussion}

\subsection{SEM studies}

SEM was employed to characterize the surface morphology and cross-section structure of the membrane with images shown in Figure 2. As demonstrated in Figures 2 (a, b), the ultrafiltration membrane surface was uniform and smooth, whereas the composite nanofiltration membrane was rough. During IP reaction, many tiny holes and mountain-like micro-projections appeared on the membrane surface. These holes and projections improved the surface roughness of the resultant membrane and increased the effective membrane area. Figure 2(c) shows that the large pores of support membranes have an asymmetrical structure covered by a thin and increasingly compact layer. Owing to this unique asymmetric structure, composite nanofiltration membranes possess low operating pressure, high rejection rates, and flux [14]. The surface of the base film synthesized a thin functional layer at the interface during the polymerization reaction.

\subsection{AFM analysis}

To complement SEM, AFM was used to describe the topological features of the membrane surface. The 3D scan images of the membranes are shown in Figure 3, which evidently shows that the composite nanofiltration membranes with $0 \%$ of $\mathrm{Na3PO} 4$ were significantly dense and had less surface projections and uniformity. Figures $3(\mathrm{~b}$, c) show that the introduction of Na3PO4 generated many small cone-shaped and nodular structures on the membrane surface and therefore increased the effective membrane area of nanofiltration and hydrophilicity of the film [15]. 


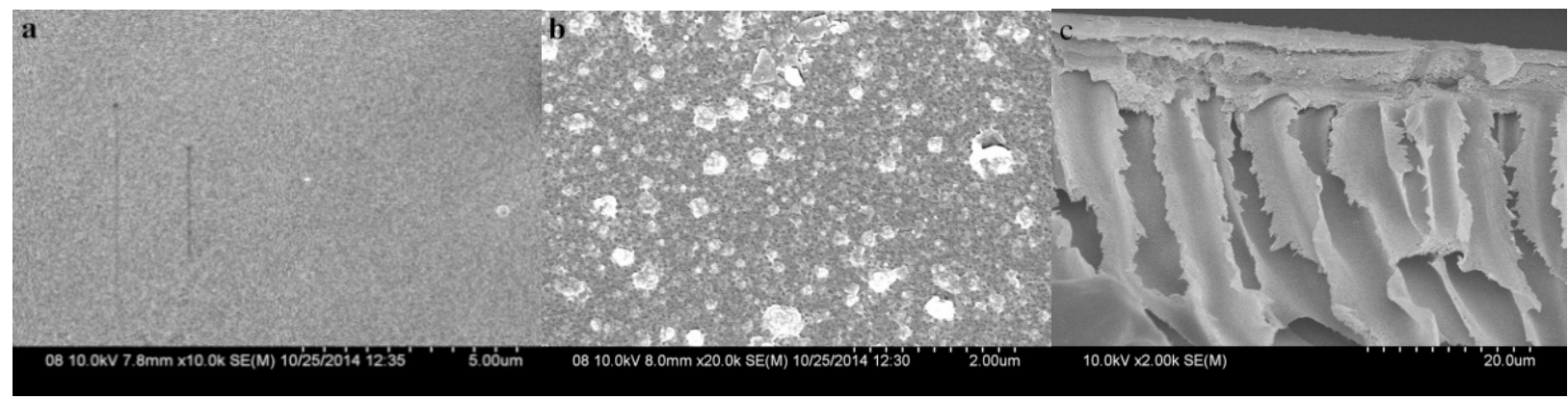

Fig. 2 SEM images of base film and composite nanofiltration membrane

(a. Surface of base film; b. Surface of composite nanofiltration membrane; c. Section of composite nanofiltration)
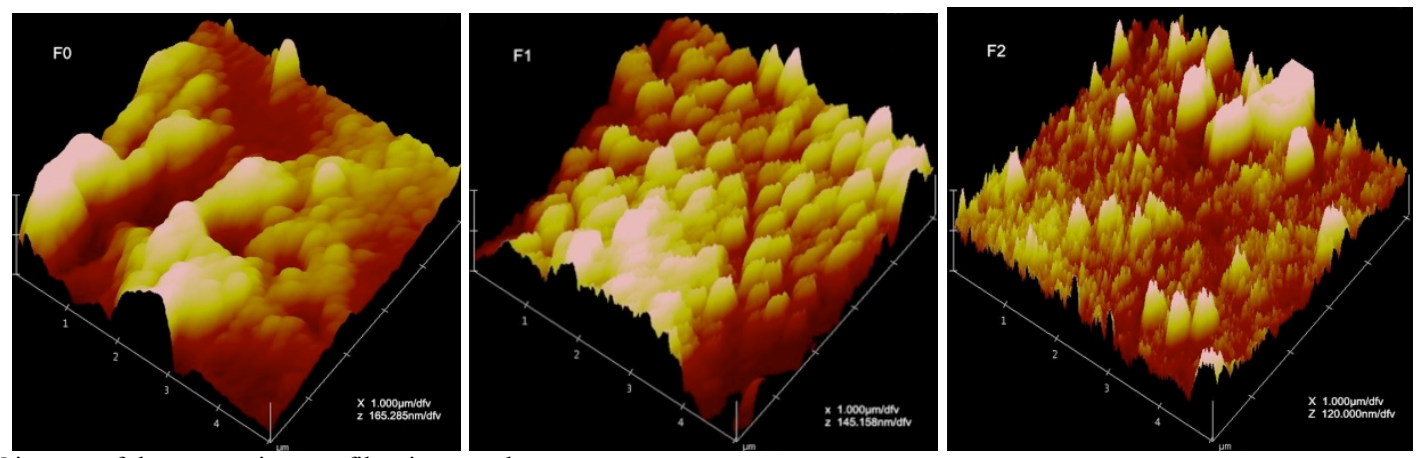

Fig. 3 AFM images of the composite nanofiltration membrane

(a. Composite nanofiltration with $0 \%$ of $\mathrm{Na}_{3} \mathrm{PO}_{4} ; \mathrm{F} 1 ; \mathrm{b}$. Composite nanofiltration with $0.5 \%$ of $\mathrm{Na}_{3} \mathrm{PO}_{4}$; F2; c. Composite nanofiltration with $1.5 \%$ of $\left.\mathrm{Na}_{3} \mathrm{PO}_{4}\right)$

\subsection{Water contact angle measurement}

Contact angle was measured to characterize the surface hydrophilicity of the membranes. A small water contact angle generally implies great membrane hydrophilicity. The data in Table 1 indicate a strong effect of $\mathrm{Na}_{3} \mathrm{PO}_{4}$ on the hydrophilicity of nanofiltration membranes (Table 1, Figure 4). $\mathrm{Na}_{3} \mathrm{PO}_{4}$, as an acid acceptor, neutralized the $\mathrm{HCl}$ generated during IP. For IP without $\mathrm{Na}_{3} \mathrm{PO}_{4}$, the PIP in the aqueous phase was consumed by $\mathrm{HCl}$ that slowed down the rate of IP reaction and negatively influenced the formation of poly PIP amide by decreasing the hydrophilicity of the composite nanofiltration membrane [16]. The water contact angle of the composite nanofiltration membrane increased with the content of $\mathrm{Na}_{3} \mathrm{PO}_{4}$ after exceeding 2\%. Such increase can be attributed to the excess $\mathrm{Na}_{3} \mathrm{PO}_{4}$, which led to the hydrolysis of polyhydric chloride during polymerization; thus, the hydrophilicity of the skin layers decreased.

Table 1 Water contact angle of composite nanofiltration membrane with varying $\mathrm{Na}_{3} \mathrm{PO}_{4}$ contents

\begin{tabular}{c|c|c|c|c|c|c}
\hline $\mathrm{Na}_{3} \mathrm{PO}_{4}$ concentration $/(\%)$ & 0 & 0.5 & 1 & 1.5 & 2 & 2.5 \\
\hline water contact angle $\theta /\left(^{\circ}\right)$ & 46.1 & 37.8 & 31.4 & 30.5 & 32.7 & 42.4 \\
\hline
\end{tabular}
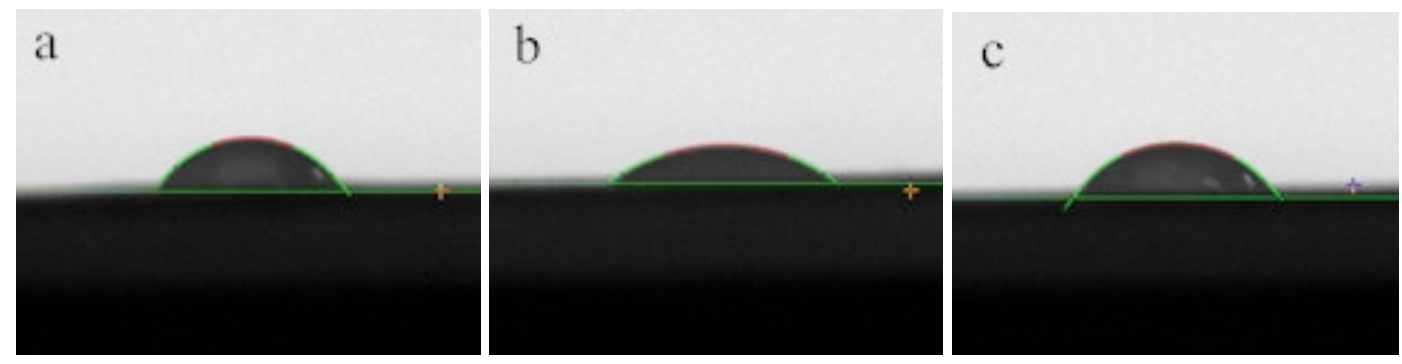

Fig. 4 Images of water contact angle of the composite nanofiltration membrane

(a. Water contact angle composite nanofiltration with $0 \%$ of $\mathrm{Na}_{3} \mathrm{PO}_{4}$; b. Water contact angle composite nanofiltration with $1.5 \%$ of $\mathrm{Na}_{3} \mathrm{PO}_{4}$; c. Water contact angle composite nanofiltration with $2.5 \%$ of $\mathrm{Na}_{3} \mathrm{PO}_{4}$ )

\subsection{Effects of monomer concentration in the aqueous} phase

With the different concentrations of PIP (i.e., $0.25 \%, 0.5 \%$, $1 \%, \quad 1.5 \%, 2 \%$, and $2.5 \%)$, composite nanofiltration membranes were prepared with $1.5 \%$ of $\mathrm{Na}_{3} \mathrm{PO}_{4}$ concentration, $0.25 \%$ of TMC concentration, and thermal

treatment at $70{ }^{\circ} \mathrm{C}$ for $12 \mathrm{~min}$. The results are shown in Figure 5.

As illustrated in Figure 5, when the PIP concentration increased, the pure water flux of the resultant composite nanofiltration membrane decreased and the retention rate 
reduced after reaching a maximum of $1 \%$ while keeping other conditions constant. Given that the film properties were dependent on the functional layer formed in the IP, the reaction was rapid with the rise in PIP concentration. PIP and TMC reacted on the surface of the membrane and generated a dense network, which caused the decrease in membrane flux but not the increase in retention rate [17]. When the content of PIP exceeded $1.5 \%$, the crosslinking density of the membrane surface was excessive. With further increases in PIP concentration, the membrane flux was further reduced, whereas the retention rate had no significant increases. The optimal concentration of PIP ranged from $1 \%$ to $1.5 \%$.

With various concentrations of $\mathrm{Na}_{3} \mathrm{PO}_{4}$ (i.e., $0.25 \%$, $0.5 \%, 1 \%, 1.5 \%, 2 \%$, and $2.5 \%$ ), different composite nanofiltration membranes were also prepared with $1.5 \%$ of PIP, $0.25 \%$ of TMC, and thermal treatment at $70{ }^{\circ} \mathrm{C}$ for 12 min. The obtained results are displayed in Figure 6.

$\mathrm{HCl}$ was produced during PIP and TMC reactions [18]. As an acid acceptor, $\mathrm{Na}_{3} \mathrm{PO}_{4}$, neutralized the $\mathrm{HCl}$ generated during IP. The effects of the different concentrations of $\mathrm{Na}_{3} \mathrm{PO}_{4}$ on the nanofiltration membrane were investigated to determine the optimal $\mathrm{Na}_{3} \mathrm{PO}_{4}$ content. When the concentration of $\mathrm{Na}_{3} \mathrm{PO}_{4}$ was excessively low, the PIP in aqueous phase was consumed by $\mathrm{HCl}$ and a considerably high concentration of $\mathrm{Na}_{3} \mathrm{PO}_{4}$ led to a high $\mathrm{pH}$ of the system due to the hydrolysis of polycarboxylic acid chloride. The results showed that the addition of $\mathrm{Na}_{3} \mathrm{PO}_{4}$ promoted the generation of a high quality functional layer with an optimal concentration of $\mathrm{Na}_{3} \mathrm{PO}_{4}$ at $1.5 \%$.

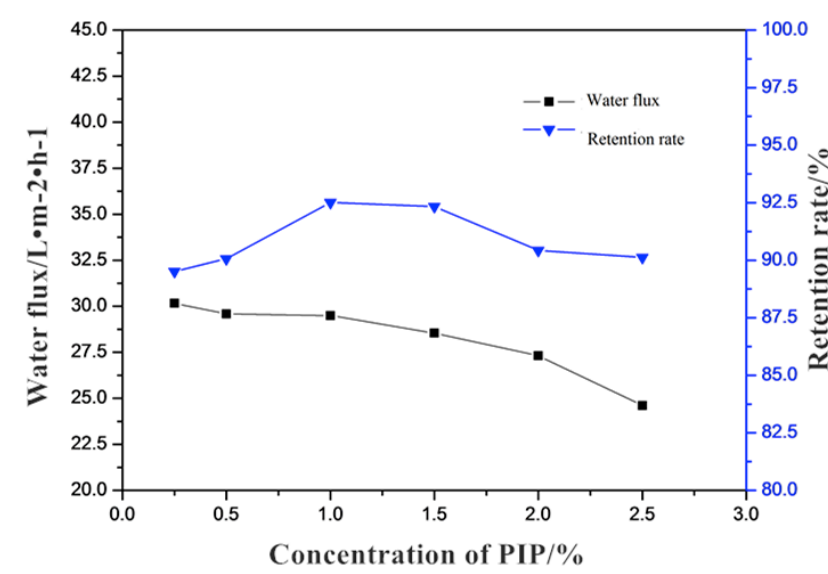

Fig. 5 Effect of concentration of PIP on flux and retention rates of composite nanofiltration membrane

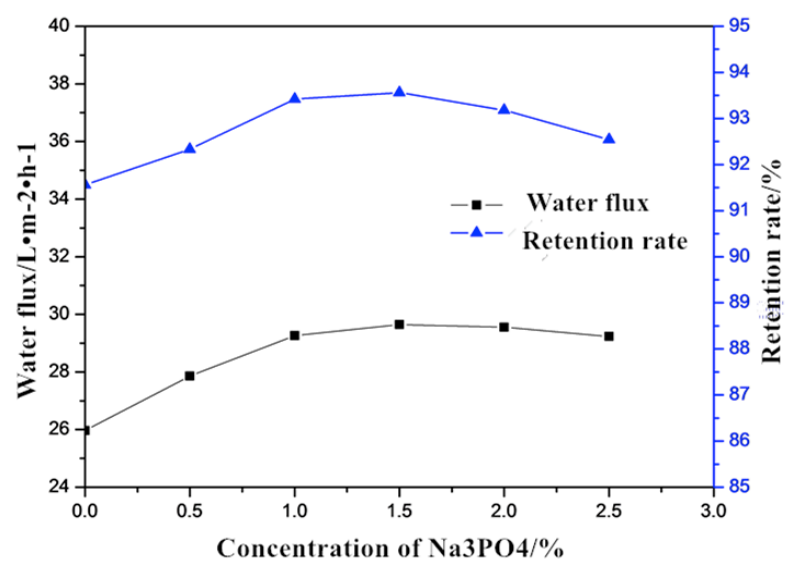

Fig. 6 Effects of concentration of $\mathrm{Na}_{3} \mathrm{PO}_{4}$ on flux and retention rate of composite nanofiltration membrane
4.5 Effect of TMC concentration in the organic phase

With the various concentrations of TMC (i.e., $0.25 \%, 0.5 \%$, $1 \%, 1.5 \%, 2 \%$, and $2.5 \%$ ), composite nanofiltration membranes were prepared with $1.5 \%$ of PIP, $0.25 \%$ of $\mathrm{Na}_{3} \mathrm{PO}_{4}$, and thermal treatment at $70{ }^{\circ} \mathrm{C}$ for $12 \mathrm{~min}$. The results are shown in Figure 7.

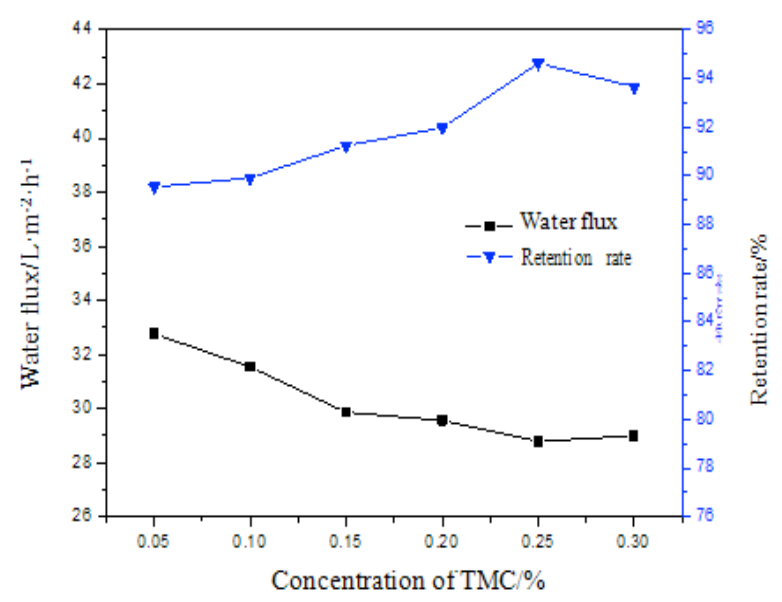

Fig. 7 Effects of concentration of TMC on flux and retention rates of composite nanofiltration membrane

Figure 7 shows that with the increase in TMC concentration, the retention rate increased to a peak at $0.25 \%$ and then decreased slightly. Pure water flux decreased with the increase in TMC concentration, but increased slightly at $0.30 \%$. When TMC increased to a certain concentration, PIP was depleted completely; thus, the surplus TMC led to hydrolysis during which acid chloride was converted into carboxyl groups, which damaged the functional layer of the membrane and led to the decline of rejection [19].

\subsection{Effects of reaction time in IP}

With various aqueous phase reaction times (i.e., 15, 30, 45, $60,75,90,105$, and $120 \mathrm{~s}$ ), composite nanofiltration membranes were prepared with $1.5 \%$ of PIP, $0.25 \%$ of $\mathrm{Na}_{3} \mathrm{PO}_{4}, 0.25 \%$ of TMC, thermal treatment at $70{ }^{\circ} \mathrm{C}$ for 12 min, and organic phase reaction time of $1 \mathrm{~min}$. The aqueous phase reaction time was then fixed at $1 \mathrm{~min}$, and different composite nanofiltration membranes were prepared by changing the organic phase reaction time for $15,30,45,60$, $75,90,105$, and $120 \mathrm{~s}$. The results are indicated in Figures 8 and 9 .

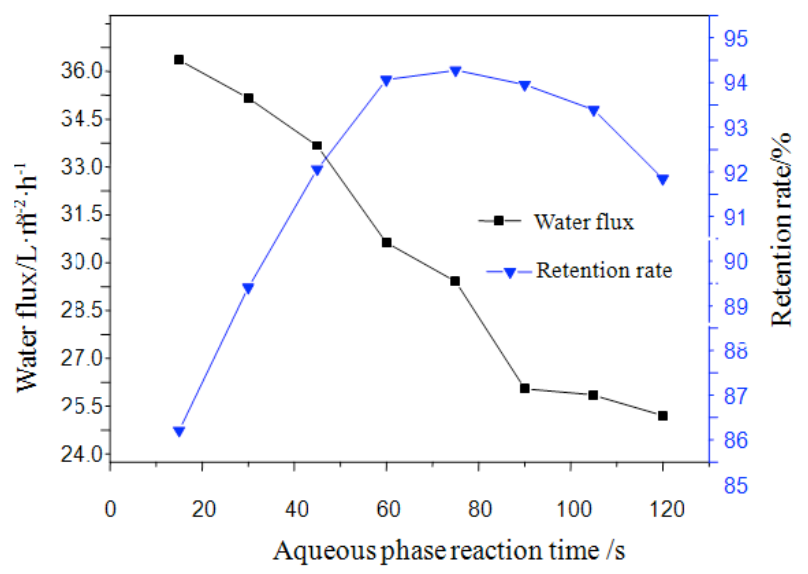

Fig. 8 Effects of aqueous phase reaction time on composite nanofiltration membrane 


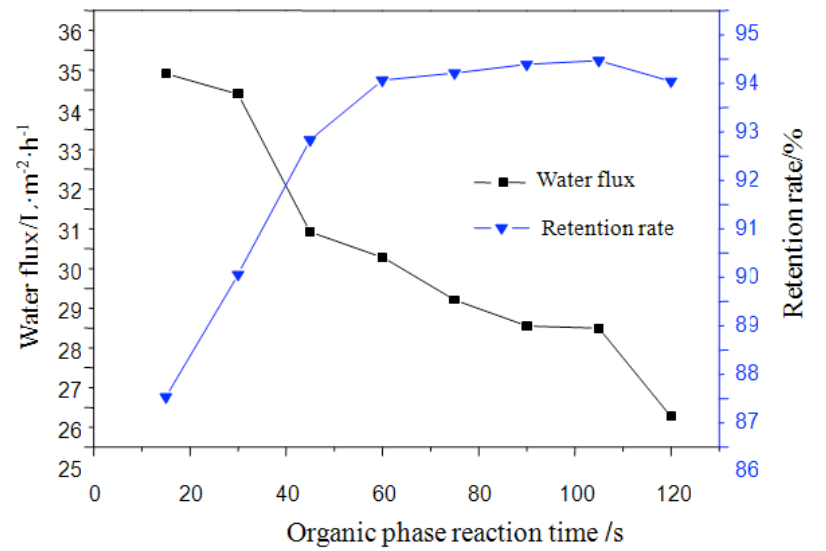

Fig. 9 Effects of organic phase reaction time on composite nanofiltration membrane

As indicated in Figures 8 and 9, with the increase in reaction time, the flux decreased, whereas the rejection rate increased and finally stabilized with the extension of time. The flux decrease was due to the extended processing time of the aqueous phase when additional amounts of PIP were adsorbed by the base film, resulting in a significantly compact surface mesh structure, which led to low water transmission rate and flux. Therefore, when the pore size of the base film was reduced, the rejection rate increased. When the base film was saturated with PIP adsorption, the interception rate increased and stabilized with the extension of the processing time of aqueous phase [20]. The base film was treated by organic phase after aqueous phase processing. Polymerization reaction occurred between TMC and PIP. With the increase in reaction time, the polymer generated on the surface of the membrane became dense, thereby decreasing the flux but increasing the interception rate. When PIP was consumed completely, polymerization ceased. Finally, the optimal processing time of the aqueous or organic phase varied between 60 and $70 \mathrm{~s}$.

\subsection{Effects of thermal treatment in IP}

A series of composite nanofiltration membranes was prepared with PIP, $\mathrm{Na}_{3} \mathrm{PO}_{4}$, and TMC concentrations of $1.5 \%, 0.25 \%$, and $0.25 \%$, respectively, by varying the thermal treatment time from $4 \mathrm{~min}$ to $16 \mathrm{~min}$ at $70{ }^{\circ} \mathrm{C}$. Another series of composite nanofiltration membranes was prepared by changing the thermal treatment temperature from $50{ }^{\circ} \mathrm{C}$ to $90{ }^{\circ} \mathrm{C}$, with treatment time fixed at $10 \mathrm{~min}$. Pure water flux and rejection rate were measured. The results are shown in Figures 10 and 11.

Figure 10 shows that with the extension of thermal treatment time, the water flux decreased and then increased, whereas the rejection rate followed the opposite trend. With the increase in thermal treatment time, a small aperture was formed as a result of heat shrink at a certain thermal treatment temperature. Molecular thermal motion promoted the reaction rate of IP and led to the generation of polypiperazine amide and a dense membrane surface, resulting in flux reduction and rejection rate enhancement. Nevertheless, when the thermal treatment continued, polypiperazine amide began to decompose and the macromolecular polymer on the film surface began to decrease, making the functional layer structure gradually loosen and peel from the film surface. This condition explains the sharp decrease in interception rate and the rapid rise in pure water flux.
Figure 11 indicates that when the thermal treatment temperature increased, the pure water flux reduced gradually and the withholding rate rose to the maximum of $75^{\circ} \mathrm{C}$ and then decreased slowly. With the temperature increase in the low reaction temperature range, the molecular thermal motion increased as well as the reaction rate, but the diffusion resistance of the surface functional layer of the base film was reduced. All these activities promoted the generation of PIP amide, the polymer, and the crosslinking degree on the surface; thus, the interception rate was increased greatly but the flux was decreased [21]. When the temperature rose to a certain value, the temperature was exorbitant, the aggregation of macromolecule started to decompose, and the functional layer density was reduced due to the depressed interception rate.

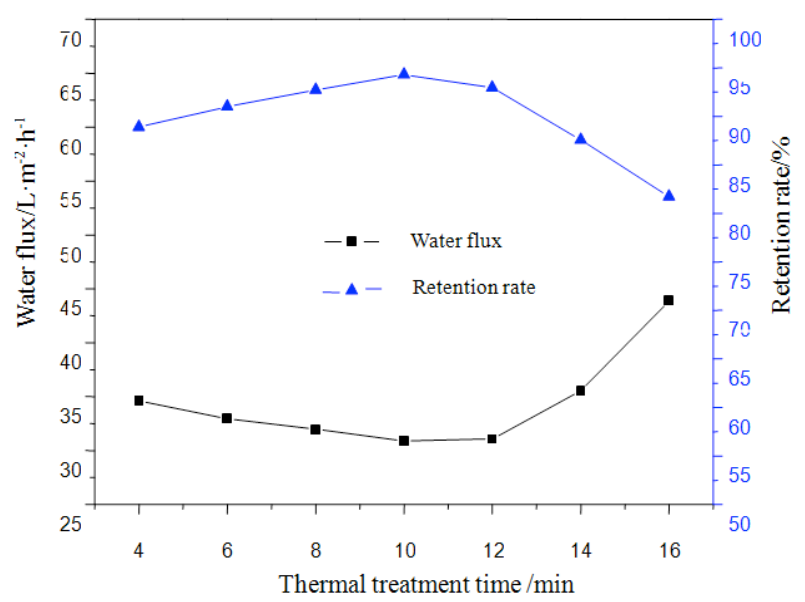

Fig. 10 Effect of thermal treatment time on composite nanofiltration membrane

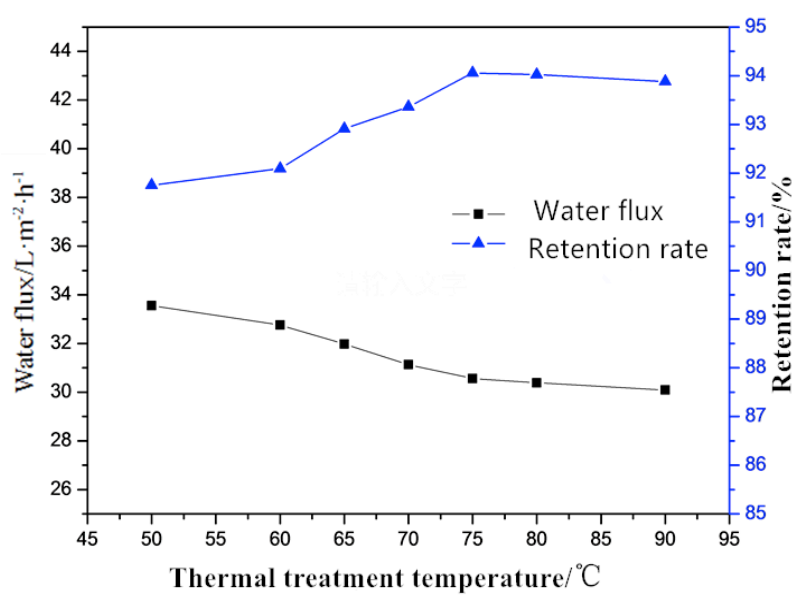

Fig. 11 Effect of thermal treatment temperature on composite nanofiltration membrane

\section{Conclusions}

To improve the nanofiltration membrane performance and hydrophilicity, this paper studied the preparation and characterization of a hydrophilic composite nanofiltration membrane by adding $\mathrm{Na}_{3} \mathrm{PO}_{4}$ in the aqueous phase during IP. The surface morphology and cross-section structure of the membrane were characterized with SEM and AFM, respectively. The main conclusions drawn are as follows:

(1) Adding $\mathrm{Na}_{3} \mathrm{PO}_{4}$ in the aqueous phase during IP increases the hydrophilicity and pure water flux of the membrane. $\mathrm{Na}_{3} \mathrm{PO}_{4}$ affects the surface morphology and internal structure of the membrane, thereby improving its hydrophilicity. 
(2) SEM results showed that a compact and thin functional layer was formed on the ultrafiltration membrane surface. AFM 3D scan images showed that the addition of $\mathrm{Na}_{3} \mathrm{PO}_{4}$ generated many small cone-shaped and nodular structures on the membrane surface, which enhanced the effective surface area and water flux. The water contact angle of the membrane was also improved obviously.

(3) The optimal preparation conditions for hydrophilic composite nanofiltration membranes were confirmed as the concentrations of $\mathrm{Na}_{3} \mathrm{PO}_{4}, \mathrm{PIP}$, and TMC at $1.5 \%, 1 \%$, and $0.25 \%$, respectively, reaction time of $60 \mathrm{~s}$, thermal treatment temperature ranging from $70{ }^{\circ} \mathrm{C}$ to $80{ }^{\circ} \mathrm{C}$, and thermal treatment time of $12 \mathrm{~min}$. This type of hydrophilic nanofiltration membrane can improve the efficiency of water treatment, can enhance membrane fouling, and has excellent prospects for application in the water treatment process.

In sum, employing appropriate organic salts, such as $\mathrm{Na}_{3} \mathrm{PO}_{4}$, can significantly enhance the performance of nanofiltration membranes. Owing to time constraints, part of the work remains unfinished. Thus, related problems need further research, including inorganic salt ion migration during membrane application, influence of inorganic salt ions on membrane pore structure, and so on.

\section{Acknowledgements}

This work was financially supported by the National Natural Science Foundation of China (41362003) and the Foundation of Jiangxi University of Science and Technology (NSFJ2015-G04).

\section{References}

1. Liang, X., Li J. M., Chen Z., "Development of novel materials for nanofiltration membranes". Journal of Filtration \& Separation, 16(3), 2006, pp.18-21.

2. Wu, D. H., Yu, S., Darren, L., Feng, X. S., "Thin film composite nanofiltration membranes fabricated from polymeric amine polyethylenimine imbedded with monomeric amine piperazine for enhanced salt separations". Reactive and Functional Polymers, 86(1), 2015, pp.168-183.

3. Mahdie, S., Vahid, V., Alireza, K., Majid, E., "Development of a novel high flux and fouling-resistant thin film composite nanofiltration membrane by embedding reduced graphene oxide/TiO ${ }_{2}$ ". Separation and Purification Technology, 154(5), 2015, pp.96-107.

4. Guan, S. S., Zhang, S., Liu, P., Zhang, G. Z., Jian, X. G., "Effect of additives on the performance and morphology of sulfonated copoly (phthalazinone biphenyl ether sulfone) composite nanofiltration membranes". Applied Surface Science, 295(5), 2014, pp.130-136.

5. A.K. Holda, I.F.J. Vankelecom., "Influence of Low and High Molecular Weight Additives in the Synthesis of sRNF-Membranes Via Phase Inversion". Procedia Engineering, 44, 2012, pp.356-1357.

6. B. Van der Bruggen, "Chemical modification of polyethersulfone nanofiltration membranes: a review". Journal of Applied Polymer Science. 114(1), 2009, pp.630-642.

7. Yunos, M.Z., Harun, Z., Basri, H., Ismail, A. F., "Studies on fouling by natural organic matter (NOM) on polysulfone membranes: Effect of polyethylene glycol (PEG)". Desalination, 333(1), 2014, pp.36-44.

8. Ahmad, A. L., Abdulkarim, A. A., Ooi, B. S. Ismail, S., "Recent development in additives modifications of polyethersulfone membrane for flux enhancement". Chemical Engineering Journal, 223(1), 2013, pp.246-267.

9. Alghunaim, A., Newby, B. Z., "Cross-linked polystyrene sulfonic acid and polyethylene glycol as a low-fouling material. Colloids and SurfacesB:". Biointerfaces, 140(1), 2016, pp.514-522.

10. Law, Y. N., Abdul, W. M., Ching, Y. N.. "A review on nanofiltration membrane fabrication and modification using polyelectrolytes: Effective ways to develop membrane selective barriers and rejection capability". Advances in Colloid and Interface Science, 197-198(9), 2013, pp.85-107.

11. Hu, L. L., Zhang, S. H., Han, R. L., Jian, X. G., "Preparation and performance of novel thermally stable polyamide/PPENK composite nanofiltration membranes”. Applied Surface Science, 258(1), 2012, pp.9047-9053.

12. Pourjafar, S., Rahimpour, A., Jahanshahi, M., "Synthesis and characterization of PVA/PES thin film composite nanofiltration membrane modified with $\mathrm{TiO}_{2}$ nanoparticles for better performance and surface properties". Journal of Industrial and Engineering Chemistry, 18(4), 2012, pp.1398-1405.

13. Andrade, P. F., de Faria, A. F., Oliveira, S. R., Arruda, M. A. Z., do Carmo Gonçalves, M., "Improved antibacterial activity of nanofiltration polysulfone membranes modified with silver nanoparticles". Water Research, 81(15), 2015, pp.333-342.

14. Gao, X. L., Wang, W. W., Chen, X. L., Xu, J., Preparation of sodium alginate/polysulfone (PS) composite nanofiltration membrane by IP". Membrane Science and Technology, 31(4), 2011, pp.27-30.

15. Li, X., Cao, Y. M.. "A novel composite nanofiltration membrane prepared with PHGH and TMC by interfacial polymerization". Journal of Membrane Science, 466(1), 2014, pp.82-91.

16. Van Wagner, E. M., Sagle, A. C., Sharma, M. M., La, Y. H., Freeman, B. D., "Surface modification of commercial polyamide desalination membranes using poly-(ethylene glycol) diglycidyl ether to enhance membrane fouling resistance". Journal of Membrane Science, 367(1), 2011, pp.273-287.

17. Yang, J. Zeng, X. Q., Wang, L. H., Li, D. L., Wang, W., "Preparation of polypiperazine-amide composite nanofiltration membrane through Interfacial polymerization". Chemical research and application, 22(4), 2010, pp.458-459.

19. Yang, B., Yang, W.T., "Preparation of temperature-sensitive track membrane by bulk Photo grafting". Journal of Beijing university of chemical technology, 30(2), 2003, pp.35-39.

19. Fang, P., Cao, B., Dan, Y., Pan, K., "Interfacial Polymerization of Polyamide Nanofiltration Membrane". Polymer materials science and engineering, 27(10), 2011, pp.2-3.

20 Yang, S., Zhang, Y. F., Zhang, Y. P., "Research of polypiperazine amide composite Nanofiltration membrane". Journal of Tian jin polytechnic university, 27(5), 2008, pp.9-13.

21. Al Malek, S. A., Seman, M. A., Johnson, D., Hilal, N., "Formation and characterization of polyethersulfone membranes using different concentrations of polyvinylpyrrolidone". Desalination, 288(1), 2012, pp.31-39. 